\title{
Structural assessment of a lattice tower for a small, multi-bladed wind turbine
}

\author{
Redeemer Axisa $^{1} \cdot$ Martin Muscat $^{1}\left(\mathbb{D} \cdot\right.$ Tonio Sant $^{1} \cdot{\text { Robert N. } \text { Farrugia }^{2}}^{2}$
}

Received: 17 November 2016/Accepted: 30 May 2017/Published online: 8 June 2017

(c) The Author(s) 2017. This article is an open access publication

\begin{abstract}
This paper deals with a limit load assessment and preliminary experimental testing of a lattice-type steel tower used to support a newly designed, prototype small wind turbine having nine blades and a rotor diameter of $3.4 \mathrm{~m}$. Small wind turbine and structural engineering codes of standards were followed with the purpose of implementing a system that meets European Union countries' legislation. The supporting lattice tower structure was subjected to a full-scale load test. This test verified that the structure can withstand the design loads. The finite element software ANSYS Mechanical was used to model and analyse the actual structure, and to determine the possible failure modes and their associated load levels. The most probable mode of failure for such a structure was found to be elastic buckling of the main corner posts. A number of finite element lattice tower models utilising different modelling strategies and solution methods are presented and analysed. The paper highlights the importance of using non-linear analyses as opposed to linear analyses and gives recommendations on the most reliable available modelling technique. Computational analyses' results are compared with measurements from a full-scale test on the tower structure.
\end{abstract}

Keywords Small wind turbine Lattice tower structure Buckling · Field testing

Martin Muscat

martin.muscat@um.edu.mt

1 Faculty of Engineering, University of Malta, Msida MSD2080, Malta

2 Institute for Sustainable Energy, University of Malta, Marsaxlokk MXK1531, Malta

\section{List of symbols}

$[K] \quad$ Structural stiffness matrix

$[S] \quad$ Stress stiffness matrix

$\lambda_{i} \quad i$ th eigenvalue

$\Psi_{i} \quad i$ th eigenvector of displacements

$N_{\mathrm{b}, \mathrm{Rd}} \quad$ Buckling resistance of a truss member

A Truss member cross-sectional area $\left[\mathrm{m}^{2}\right]$

$f_{\mathrm{y}} \quad$ Yield strength of material $\left[\mathrm{N} / \mathrm{m}^{2}\right]$

$f_{\mathrm{u}} \quad$ Ultimate strength of material $\left[\mathrm{N} / \mathrm{m}^{2}\right]$

$\gamma_{\mathrm{M} 1} \quad$ Partial material factor of safety

$\bar{\lambda} \quad$ Non-dimensional slenderness ratio

$\sigma_{\mathrm{y}} \quad$ Yield stress $\left[\mathrm{N} / \mathrm{m}^{2}\right]$

$N_{\text {cr }} \quad$ Eigenvalue critical buckling load for a strut having pinned boundary conditions

$\chi \quad$ Reduction factor for compression members

$\alpha \quad$ Constant imperfection factor

$\eta \quad$ Imperfection parameter

$M$ shaft Bending moment acting on wind turbine shaft [N m]

$M x-$ shaft Torque acting on wind turbine shaft $[\mathrm{N} \mathrm{m}]$

$F_{x-\text { shaft }}$ Thrust load on wind turbine rotor in the parked position $[\mathrm{N}]$

$V_{\text {ref }} \quad$ Reference wind speed averaged over $10 \mathrm{~min}$ $\left[\mathrm{m} / \mathrm{s}^{1}\right]$

$V_{\text {avg }} \quad$ Annual average wind speed at hub height $\left[\mathrm{m} / \mathrm{s}^{1}\right]$

\section{Abbreviations}

CWM Chicago windmill

FE Finite element

FEA Finite element analysis

ID Inside diameter

OD Outside diameter

SLM Simple load model

SWT Small wind turbine 
MRRA Ministry for resources and rural affairs IEC International Electrotechnical Commission

\section{Introduction}

The wind-driven water pump (Fig. 1) was introduced to the Maltese countryside with the main purpose of extracting water from the aquifer for agricultural irrigation purposes. Most of these wind pumps are no longer in use mainly because of the introduction of the electric water pump and the extension of the electricity grid. Over the years most of these wind pumps have been abandoned and left to deteriorate.

Driven by the motivation to revamp these wind machines as part of the country's rural landscape and using the finite element software ANSYS Mechanical [1], the authors have designed and constructed a nine bladed wind turbine system that resembles the American wind machines of old, but that generates electricity, feeding the national electrical grid [2]. The prototype wind turbine is shown in Fig. 2.

The structure used to support the turbine is a $15-\mathrm{m}$ tapering lattice-type tower (Fig. 3). It has a $3 \times 3 \mathrm{~m}$ base with four main legs consisting of $50 \times 50 \times 5 \mathrm{~mm}$ steel angle sections. $30 \times 30 \times 5 \mathrm{~mm}$ angle sections were used for the lower cross and horizontal members, and $30 \times 8 \mathrm{~mm}$ flat bars were utilised for the upper cross members. The designation of the tower structural members is shown in Fig. 4. On the top of the tower there is a vertical mast made out of seamless schedule 40 $(141.20 \mathrm{~mm}$ OD $\times 128.2 \mathrm{~mm}$ ID) steel tube. The top mast is connected to the tower by means of a welded plate reinforced with webs. Gusset plates and bolts were used to connect the tower members together.

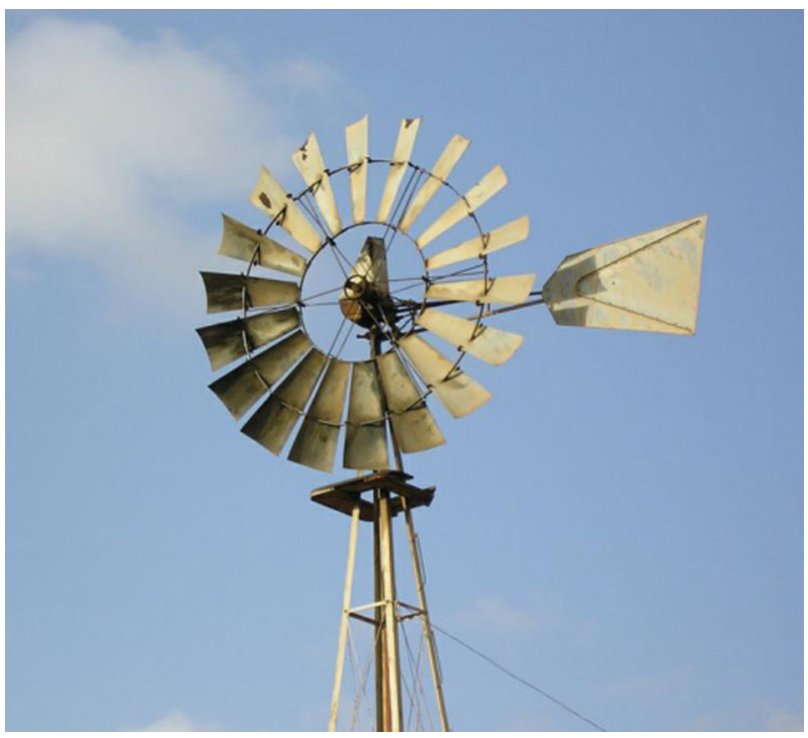

Fig. 1 Typical American-type wind-driven water pump

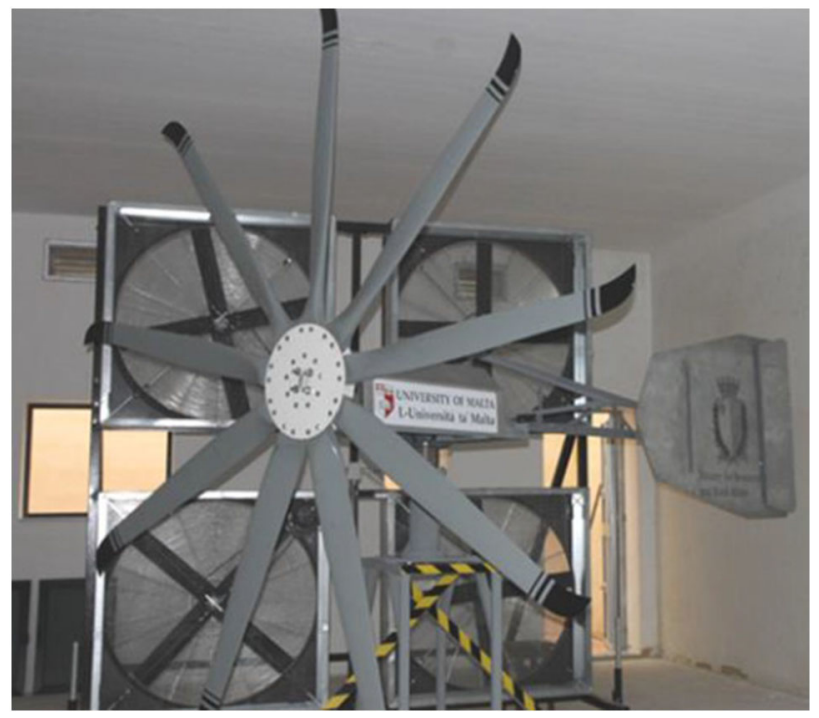

Fig. 2 The prototype wind turbine

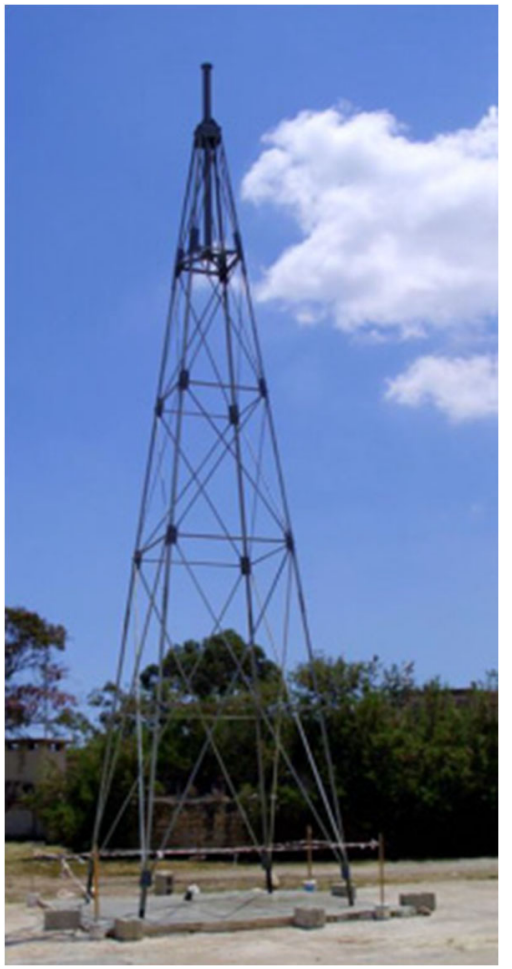

Fig. 3 The supporting lattice tower

The majority of literature sources on lattice tower are found in the telecommunications and electricity transmission fields rather than in the wind energy field. A lattice tower is a very efficient structure for carrying the dynamic and static load actions arising from environmental effects and weight of the communication and power lines, respectively. Such load actions are quite similar to wind turbine applications; however, there are some load cases 


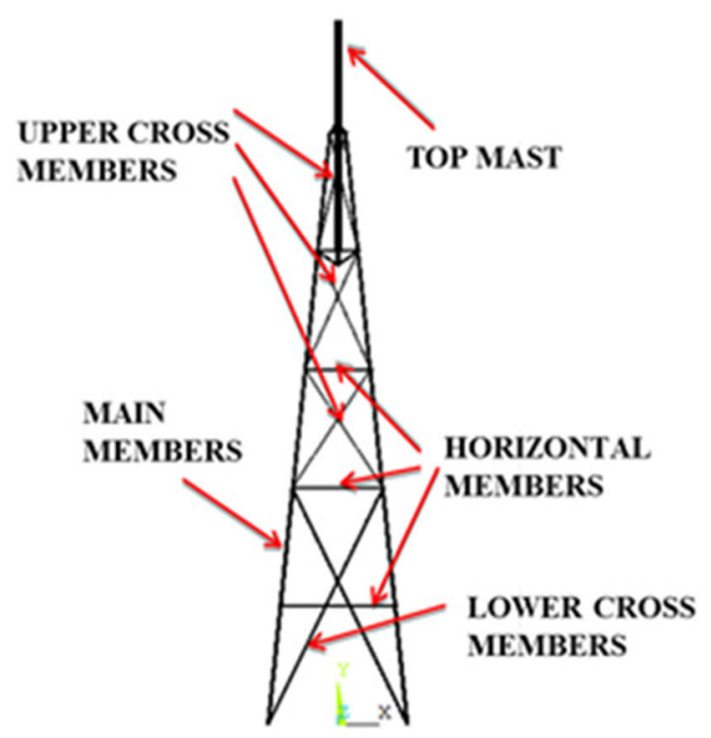

Fig. 4 Designation of the main tower members

that are only applicable to wind turbine towers. This paper is related to the application of lattice towers for supporting wind turbines. It uses the presented case study to contribute to knowledge in the area of design and analysis of such towers for small wind turbines. A design by analysis methodology is applied within the context of mandatory codes of standards. In doing so, the authors confirm knowledge reported in previous literature, while providing salient recommendations based on the analysis work described in the paper itself. Experimental testing of the lattice tower supported and confirmed the recommendations and conclusions reached by the authors.

\section{Lattice towers}

Lattice towers are used in many civil engineering applications, typically including roofing structures and telecommunications and electrical power transmission towers. These structures are suited for weight minimisation and for reducing wind resistance. For structural design and analysis of lattice towers, the current industrial tools are finite element (FE) software packages combined with established design codes [3-10]. The majority of the work in published literature with regard to lattice towers concerns the analysis of electricity transmission towers [11-19]. For the purpose of the work presented here, electricity transmission towers are particularly interesting because they have a mode of loading similar to that of wind turbines.

The general procedure for FE modelling of lattice towers is to use linear elastic uniaxial truss finite elements. These elements are used since the tower members are mainly loaded axially along their length and at the structural connections bending moments are low. The structural connections are assumed to be frictionless pin connections and the truss elements free to rotate relative to the other members [5]. Given this, any lateral loads have to be distributed as point loads on the member end connections [20]. However, the perfect pin connection seldom occurs since the structural connection behaviour always has a degree of rigidity. This is dependent on the type of the actual connection. This can be a single bolted or multiple bolted angle, or a welded connection using a gusset plate. A degree of bending moments and possibly twist are therefore present at the connections [7, 21]. Kroeker [20] investigated the secondary effects of modelling the connections as rigid instead of pinned and found that the secondary effects may lead to premature failure of electricity transmission towers.

A further difficulty arising during the analysis of towers with truss elements is the possibility of unstable assemblies forming a mechanism. During the FE solution phase, this will cause rigid body motion and the numerical solution will fail to converge. This fact is highlighted in [20] and [21]. This issue has most influence on dynamic analyses such as in a modal analysis, which is used to determine the natural frequencies of the structure. Modelling with truss elements means that the analytical structure has more dynamic degrees of freedom than in the actual case [21-24]. Two possible solutions to overcome this problem are to either use dummy members in the model to suppress the unwanted degrees of freedom or to replace the truss elements with beam elements. The dummy members usually have a small axial stiffness which is large enough to eliminate any mechanisms that tend to form, while the use of beam elements retains the bending stiffness at the connections [21]. The work in [21] focused on the different results that can be obtained even using linear analysis by just changing the element types. The lattice tower was modelled using either a model made up of solely beam elements or using a model made up of combined beam and truss elements. The main legs were modelled using beam elements, while the bracing members were modelled using truss elements. Ref. [21] reports that the eigenvalue buckling capacity of the structure with a full beam element model was overestimated when compared to the combined beam and truss model. Caution in the element choice is therefore advised.

Once the loads in all the members are obtained, these are used to design the structural connections present in the tower. These connections are designed for various modes of failure, including gusset plate tearing, bolt shearing and tension failure of the members [25]. Given that these checks are made, the next most probable failure mode for 
lattice towers is structural instability or buckling of the slender members.

Structural members are designed against the buckling mode of failure using an appropriate design standard such as the European Standard EN1993-1-1 [26]. Linear elastic finite element analysis is not sufficient when checking for this type of failure mode and non-linear analysis must then be used. This is mainly because of the geometric imperfections and eccentricities present in the structural connections. The latter is most common for towers which are fabricated from members having an angle cross section using a single bolt or welding without the use of a gusset plate. This eccentricity in the connection induces a secondary bending moment at the joint end of the members $[6,27]$. Results from actual full-scale tower tests indicate that linear static analysis is not consistent in modelling the behaviour of the structure. It is also reported that bending stresses in the members, which initially were assumed to be negligible, can be as high as the axial stresses [27-31]. Ref. [27] gives a number of reasons why the pin joint assumption does not hold for real towers. One of the main reasons is due to the main legs normally being continuous through the joint and due to the fact that, usually, more than one bolt is used in the connections, so that they should be assumed to be semi-rigid and not pinned. The bending moments at the connections are referred to as the secondorder effect.

Albermani and Kitipornchai [28] present an analytical technique that takes into account both geometric and material non-linearities. The geometric non-linearity analysis considers the effects of accumulated stresses and the effect of the changes in the geometry on the structural stiffness of the elements as the load is increased. The material non-linearity considers the effect of plasticity occurring in the sections if the elastic limit is exceeded. Their investigation was used to upgrade old towers by reinforcing them using a horizontal diaphragm bracing system. They also used their analysis to verify a new tower design which showed good agreement with the actual full-scale tower test. Very large towers considered in the literature usually use a K-type truss bracing system to support the main leg, and within these bracings there are secondary and redundant members. As discussed in [29], linear analysis calculates the forces in these secondary bracing members to be negligible. However, results from real tests show that these members are substantially loaded and play a role in the stability of the main members. In fact, in one of the full-scale tower tests carried out in [13], the main member buckled because of end tearing failure of these 'redundant' members. Other literature compares results from the non-linear structural analysis to full-scale tower tests subjected to the same load cases [6-8, 12, 15-19, 29-31]. Albermani et al. [30] concluded that the predicted failure loads and failure modes of their models were in good agreement with those obtained in tests. The same conclusion was made by Rao et al. [29], in which the forces acting on the bracing members of the tower before failure were consistent with test results. On the other hand, Rao et al.'s [31] results from the non-linear analysis slightly over-predicted the experimental buckling failure load for two of the towers analysed by a few percent. They put forward a number of observations which might have contributed to this difference, mainly bolt hole clearances, force fitting of members, non-triangulated bracings and other imperfections which were claimed to be difficult to incorporate into the finite element model.

\section{The IEC61400 design standard}

The design of the wind turbine followed the International Electrotechnical Commission's IEC 61400 design standard for small wind turbines [32], which defines a number of small wind turbine (SWT) classes in terms of wind speed and turbulence parameters.

For the island of Malta, the wind conditions for a SWT class IV were chosen. These give a $V_{\text {ref }}$ of $30.0 \mathrm{~m} / \mathrm{s}$ and a $V_{\text {ave }}$ of $6.0 \mathrm{~m} / \mathrm{s}$, as well as a number of other parameters such as the dimensionless characteristic value of turbulence intensity at $15 \mathrm{~m} / \mathrm{s}$.

Three methods can be used to calculate the load actions on the turbine for each given load case [32]. These are the 'simple load model' (SLM), 'Aero-elastic modelling' and 'Load measurements with extrapolations for extreme wind conditions'. The latter requires initial field testing, whereas the first two methodologies can be used at the design stage. For the work reported in this paper, the adopted methodology was the SLM. The SLM gives a number of load cases that need to be considered. The load cases cover a number of operating scenarios such as the normal operational mode, turbine yawing, maximum wind thrust and maximum rotational speed conditions. The load cases consist of static and dynamic loads which are caused by the airflow and its interaction with the stationary or moving parts of the wind turbine. IEC 61400-2 requires both load and material safety factors. The factor of safety for loads when the SLM method is used is 3, while the factor of safety for material is based on the amount of testing done on the material itself and by considering other issues such as corrosion and environmental effects. For the purpose of this paper, the safety factor on material was calculated to be 1.43 . The governing load cases for the designed turbine were as follows:

- Load Case B (Yawing), which is a bending moment shaft having a value of $2242 \mathrm{~N}$ m acting on the turbine drive shaft, 
- Load Case G (Shutdown braking), which is a torque load $M_{x \text {-shaft }}$ having a value of $500 \mathrm{~N}$ m acting on the drive shaft, and

- Load Case H (Parked wind loading), which is the thrust load $F_{x \text {-shaft }}$ on the rotor having a value of $3063 \mathrm{~N}$ $[2,32]$.

The design loads were used within the standard IEC 61400 [32] in order to design the main components for the turbine and nacelle. Such main components include the turbine and generator drive shaft, the yaw shaft and turbine blade root dimensions. The turbine blades were fabricated using E glass fibre composite material with steel bushes at the blade root in order to minimise damage at the rotor hub end. The turbine blades were tested as required by [32].

\section{Eigenvalue and non-linear buckling analysis}

Eigenvalue analysis predicts the theoretical buckling strength (the bifurcation point) of a structure which is idealised as elastic. For a basic structural configuration, structural eigenvalues are computed from boundary and loading conditions. Each buckling load is associated with a buckled mode shape which represents the shape a structure assumed in the buckled configuration. Eigenvalue buckling analysis yields non-conservative results when compared to the results obtained from a non-linear buckling analysis. Elastic (Euler) buckling is formulated as an eigenvalue problem with

$\left([K]+\lambda_{i}[S]\right)\left\{\Psi_{i}\right\}=0$.

In FE software, the eigenvalue solution is obtained using either Block Lanczos or the Subspace Method solvers. The conditions under which real compression members behave differ in many ways from the idealised conditions assumed in an eigenvalue buckling analysis. Real struts are affected by initial curvature, eccentric loading, residual stresses and plasticity. All these factors have a detrimental effect on the strut's buckling capacity. In a compression member, the residual compressive stresses cause premature yielding under reduced axial loads and the member buckles inelastically at a load which is less than the eigenvalue elastic buckling load. In contrast with eigenvalue buckling analysis, non-linear analysis is used in FE software in order to compute more realistic buckling loads when compared with experiments.

\section{Design of compression members according to EN1993-1-1}

For routine design of compression members, EN1993-1-1 (Eurocode 3) [26] uses a simplified design procedure which was developed from computer analysis and from correlation with test data. The formulae given in [26] for the design procedure are based on the theory for first yielding of the geometrically imperfect column. As the axial load increases, so do the stresses due to bending moments and axial stresses. The total stress in the member is composed of direct axial and bending stresses. The buckling resistance of a truss member is therefore given in EN1993-1$1: 2005$ [26] as

$N_{\mathrm{b}, \mathrm{Rd}}=\frac{\chi A f_{\mathrm{y}}}{\gamma_{\mathrm{M} 1}}$

where

$\chi=\frac{1}{\phi+\sqrt{\phi^{2}-\bar{\lambda}^{2}}}$

$\bar{\lambda}=\frac{A \sigma_{\mathrm{y}}}{N_{\mathrm{cr}}}$

$\phi=\frac{1+\eta+\bar{\lambda}^{2}}{2}$.

In order to achieve a correlation with numerical solutions, EN1993-1-1 established the imperfection parameter $\eta$ as a function of a constant factor and of the non-dimensional slenderness ratio $\bar{\lambda}$, so that

$\eta=\alpha(\bar{\lambda}-0.2)$

where $\alpha$ is a constant imperfection factor as given in [26]. Five different values for $\alpha$ are given and the choice depends on the type of cross section (whether an I-beam, hollow section, etc.), on the buckling axes, thicknesses and material strengths. These curves are based on experimental results for real columns.

\section{FE model of the tower structure}

Three different elements were used for the FE model of the tower. These were BEAM188, LINK180 and SHELL281 [1]. BEAM188 is a three-dimensional beam element formulated on Timoshenko beam theory having 6 degrees of freedom at each node: 3 are translational while the other 3 are rotational. LINK180 is a three-dimensional truss element having 3 degrees of freedom (translational) at each node. SHELL281 has 6 degrees of freedom at each node (3 translational and 3 rotational). All three elements have large deflections and stress stiffening capabilities which are required for an eigenvalue and non-linear buckling analysis. SHELL281 was used to model the plate structural components present at the top of the lattice part of the tower. These plate components were used as a transition between the top mast and the tower. The element MASS21 was used to apply the weight of the nacelle and wind turbine components on top of the tower. In conjunction with this, the gravity function in ANSYS [1] was used in the 
appropriate direction by specifying a downward acceleration of $9.81 \mathrm{~m} / \mathrm{s}^{2}$. This, together with the material density, was also required to model the tower self-weight.

The boundary conditions for all the tower models that were analysed consisted of fully constrained tower legs in all the translational and rotational degrees of freedom at the base. Differential support settlement as proposed by [28] was not taken into account since the tower foundation comprises a single, concrete foundation with reinforcement steel/mesh that was cast in situ and which was slightly larger than the square base of the tower. The geometrical model of the lattice tower is shown in Fig. 6. Tensile tests were carried out on samples of material used to fabricate the tower. The test results gave a yield strength $f_{\mathrm{y} \text {,tower }}$ of $330 \mathrm{~N} / \mathrm{mm}^{2}$, an ultimate strength $f_{\mathrm{u} \text {,tower }}$ of $470 \mathrm{~N} / \mathrm{mm}^{2}$, an elastic modulus $E$ of $208,500 \mathrm{~N} / \mathrm{mm}^{2}$ and a Poisson's ratio $v$ of 0.29 . The material for the top mast's circular hollow section has a yield stress $f_{\mathrm{y} \text {,topmast }}$ of $326 \mathrm{~N} / \mathrm{mm}^{2}$ and an ultimate strength $f_{\mathrm{u} \text {,topmast }}$ of $475 \mathrm{~N} / \mathrm{mm}^{2}$. Taking into consideration the material's factor of safety of 1.43 , the allowable stress for the tower members is therefore $230 \mathrm{~N} /$ $\mathrm{mm}^{2}$, while that for the top mast is $227 \mathrm{~N} / \mathrm{mm}^{2}$.

For the tower analysis, only the load cases associated with the total loads transferred by the wind turbine to the supporting structure were of interest. These load cases were further sub-divided, depending on the direction in which they are acting with respect to the tower orientation. The load cases which the tower was designed for were Load Case H (Parked wind loading) and Load Case B (Yawing). The wind loading effect on the individual tower members was assumed to be negligible. The partial safety factor of 3 as required by [32] was not applied to the weight of the wind turbine, as this was known from actual data.

For all models, a mesh convergence study was carried out to find the best mesh size for the tower. Figure 5 shows the results of a typical mesh convergence study when the tower model consisted of only BEAM188 elements. A

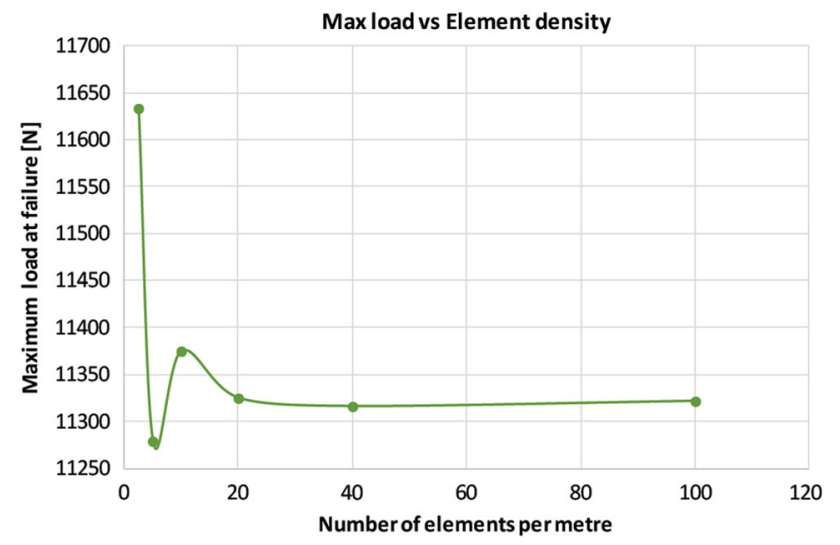

Fig. 5 Typical mesh convergence study converged, non-linear solution based on maximum load at failure (loss of equilibrium) was obtained for a beam element size of $20 \mathrm{~mm}$, giving a density of 50 elements per metre.

\section{Structural linear static tower analysis}

The main aim of the linear static analysis was to check for any stresses that exceeded the allowable stress level. The tower main members, horizontal members, lower cross members and the top mast were modelled with BEAM188 elements. On the other hand, the upper cross members were modelled with LINK180 elements because of their high slenderness ratio (Fig. 4). 8000 elements were used to generate the FE model of the tower that rendered a converged solution. A macro program using ANSYS APDL [1] was written at post-processing stage in order to list various stresses and displacements in each element and at each node, respectively.

In the elastic analysis, the tower was loaded both in a direction perpendicular to one of the four sides and also in a direction along the diagonal of the tower's square base. For these two directions of loading, the difference in maximum deflection of the tower was minimal. This means that the overall stiffness of the tower structure is almost the same when loaded perpendicularly and diagonally. This can be justified by the fact that the tower's second moment of area is approximately equal for these two directions. A maximum deflection of $55.14 \mathrm{~mm}$ occurred at the top of the mast due to thrust loading. The moment loading due to yawing caused a tip mast deflection of $17.43 \mathrm{~mm}$. Thrust loading caused higher stresses and deflections than the gyroscopic moment due to turbine yawing at the maximum rate. Figure 6 shows the tower deflection under the action

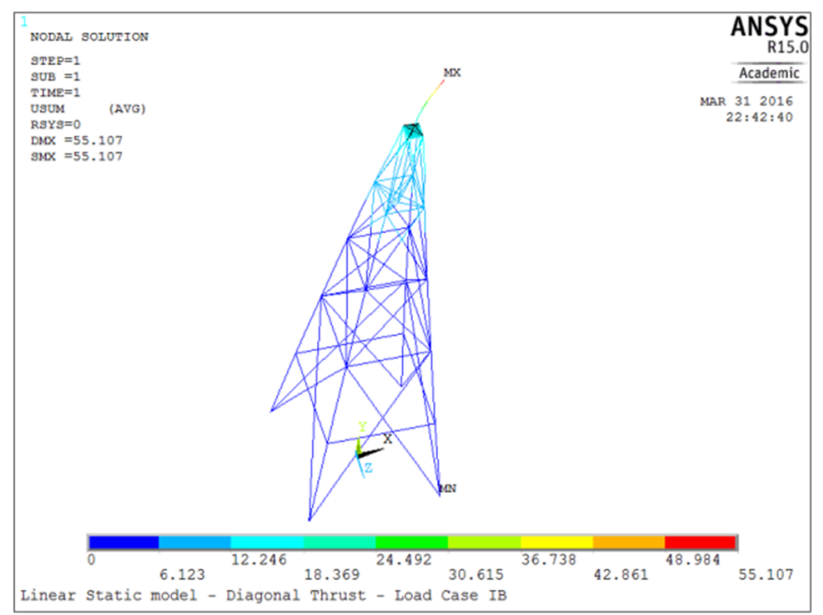

Fig. 6 Tower deflection for thrust loading along the diagonal direction 


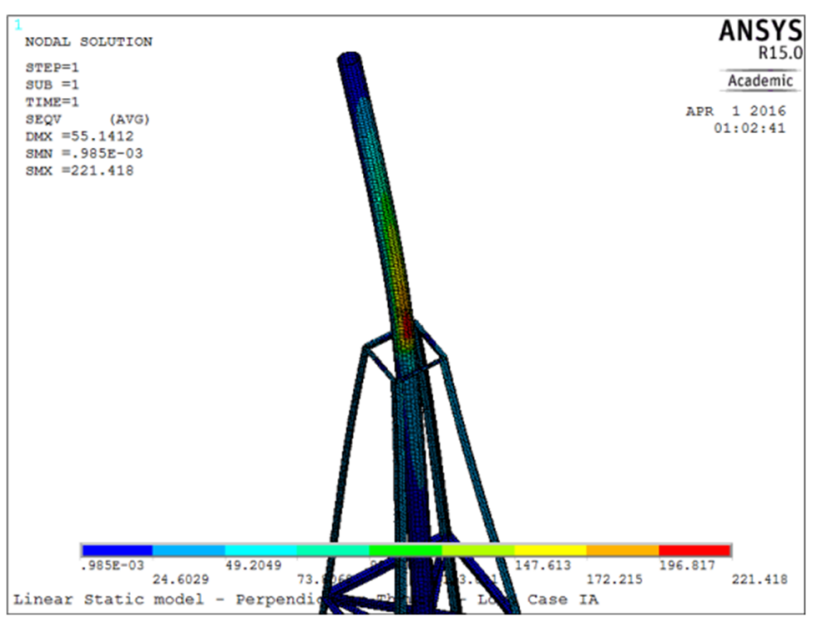

Fig. 7 von Mises stress in the top mast for thrust loading along the perpendicular direction. Shell elements at the transition are not shown for clarity

of a thrust load applied along the diagonal direction with respect to the base.

Except for small stress concentrations in the top mast/tower plate connection, the top mast was the most stressed member. All other beam/axial members in the tower had lower stress levels. The maximum stress obtained in the top mast for thrust loading was $221 \mathrm{~N} / \mathrm{mm}^{2}$ which is below the allowable limit of $227 \mathrm{~N} / \mathrm{mm}^{2}$ (see Fig. 7). Maximum axial stress in the upper cross members was of $34.63 \mathrm{~N} / \mathrm{mm}^{2}$, while the maximum bending stress in the legs was of $68.72 \mathrm{~N} / \mathrm{mm}^{2}$.

The function of the cross members in the truss system is to transfer the shearing loads acting between the tension and compressive main members. Therefore, the cross members reduce the sway motion of the tower by acting in tension or compression depending on their location. To prove this, a model of the tower was modified by eliminating the cross members completely, and a solution was obtained for the same loads. The deflected contour plot of this model is shown in Fig. 8. The total horizontal deflection at the top of the tower without cross members under the same loads increased by almost two and a half times as compared to the previous model.

The stress in the shell elements making up the truss/mast transition was the largest when compared to the rest of the tower. Figure 9 shows a detail of the upper top mast/truss connection where the von Mises stresses exceeded the allowable limit. Areas where the stress level was below the allowable threshold are greyed out. Only small stress concentration regions at the end of the webs had stress values above the allowable stress.

The highest stress resulted when the thrust load was applied along the diagonal direction with respect to the tower base. For the moment load cases, all the stresses at

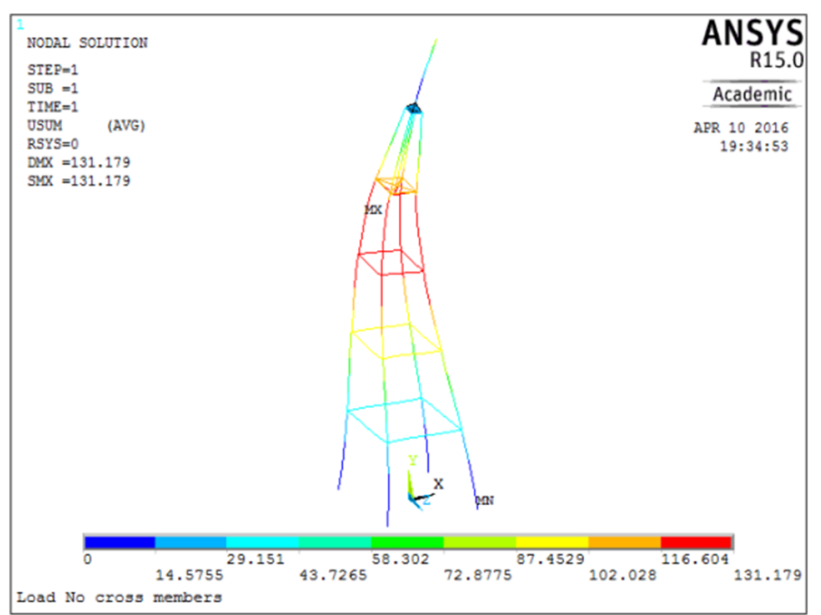

Fig. 8 Total deflection for the tower without cross members under the action of thrust loading along the diagonal direction

this location remained below the allowable limit. The high elastic stresses can be used later on in a fatigue assessment. This would be feasible once on-site records of wind loading are obtained after a testing period of at least one year.

\section{Structural non-linear buckling static tower analysis}

The structural non-linear buckling static analysis was conducted as a buckling and plastic collapse design check. Non-linear analysis required some modifications to the tower model that was used in the elastic static analysis. The main modifications were to include both geometric imperfections and material non-linearities in the model. The geometric imperfections were included to act as a perturbation to initiate buckling. These imperfections

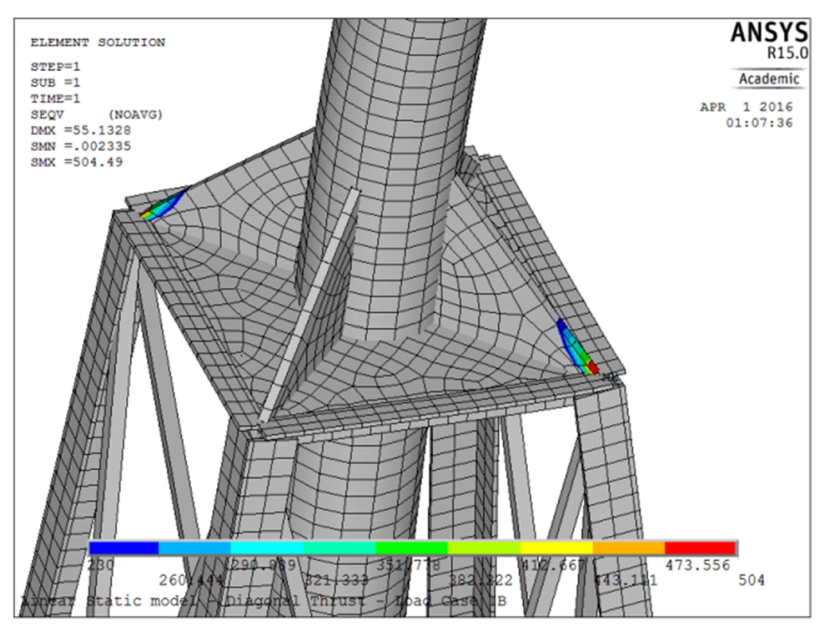

Fig. 9 von Mises stress showing the top plate connection for diagonal thrust loading 
represent the geometric imperfections present in the real structure. In order for the structure to be acceptable, geometric imperfections must be within certain tolerances as specified by the fabrication part of the relevant design code. For the work presented in this paper, two methods were used to create the imperfections in the tower model. In the first method, the mode shapes from an eigenvalue buckling analysis were used to pre-deform the structure. In the second method, an amount of deformation was imposed on the main members, mid-span between the horizontal members. This created an imposed imperfection similar to a sinusoidal form. Limits on the values of imperfections were based on Eurocode 3 [26]. Measurements of out-ofstraightness imperfections were made on the actual tower structure. During measurements, the main members were the main focus. The unsupported length for the tower's main members is $2.5 \mathrm{~m}$, and the out-of-straightness was within the range of 5 to $8 \mathrm{~mm}$. Eurocode 3 [26] requires these imperfections to fall within a length given by $L / 300$ ( $8.3 \mathrm{~mm}$ in this case), where $L$ is the unsupported length. Material non-linearity was introduced in the constitutive equations for the tower. The material was modelled as elastic perfectly plastic, exhibiting a linear stress-strain relationship up to the yield point, with a plastic modulus equivalent to zero slope beyond that point.

For the non-linear buckling analyses, the tower members were all modelled using beam elements in order to model buckling (out-of-plane deformation). The transition between the top mast and the tower was made up of shell elements as employed in the elastic analyses. For the nonlinear model, a modification was made to join the cross members as on the actual tower (Fig. 10). This was not possible with the truss element model as it caused the eigenvalue buckling analysis solution to fail to converge. This modification was included in the model since the tension member, by virtue of the midpoint connection, provides lateral support to the compression brace. If the

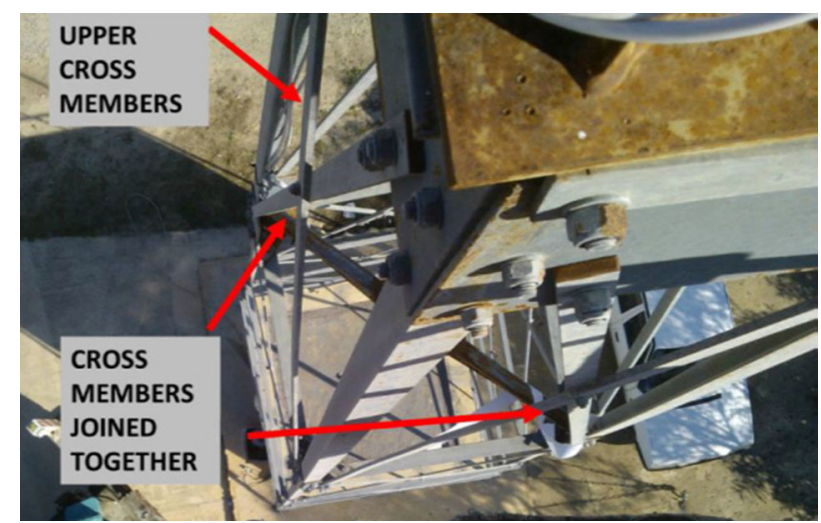

Fig. 10 Photo (taken from above the tower) showing the upper cross members joined together by a single bolt

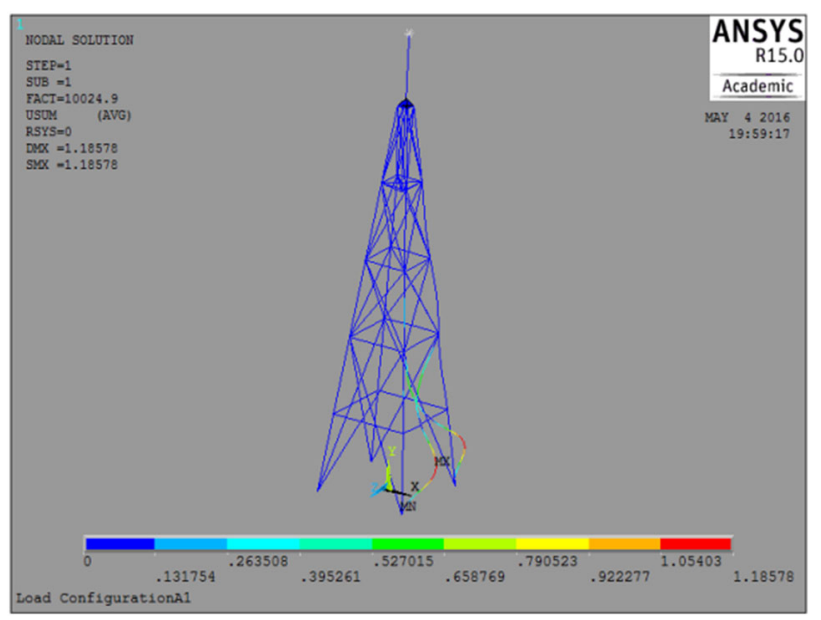

Fig. 11 Displacement contour plot for the first eigenvalue mode shape for thrust loading perpendicular to base of the tower

cross members were not connected, each member would behave independently of the other, and they would buckle in the first mode. Thus, the midpoint connection provides stability to the bracing system and efficiency to the structure as a whole [33].

Figure 11 shows one of the eigenvalue buckling modes for the tower. This and similar buckling modes were used to apply pre-deformations to the tower within the fabrication requirements of [26] to be used for the eventual nonlinear buckling analysis. Following EN1993-1-1 [26], the buckling load was calculated to be the last converged solution in a non-linear analysis, including material nonlinearities and geometric pre-deformations. The load actions applied in the non-linear analysis consisted of two load steps. In the first load step, the constant loads due to the structure self-weight and the wind turbine were applied. In the second load step, the thrust load was applied incrementally at the top of the mast. A number of sub-steps and equilibrium iterations were required, especially as the collapse load of the tower was reached.

The resulting applied load versus displacement at the tower top curves for the thrust load cases are shown in Fig. 12. Load Case 1A is for perpendicular loading, while Load Case 1B is for diagonal loading. It is worth noting that the result being presented for Load Case IB was obtained after updating the geometry with the results from the second eigenvalue mode shape. The reason for choosing this mode shape and not the first one was mainly because the eigenvalue buckling load obtained for the second mode was lower.

From these results, the most important parameter is the peak load reached, since it dictates the limit load that the tower can resist. The design thrust force to be resisted by this tower is $9189 \mathrm{~N}$ (including factor of safety). This is indicated in Fig. 12 as 'Design Load'. The peak load 
Fig. 12 Load vs displacement graphs for thrust load cases for non-linear models

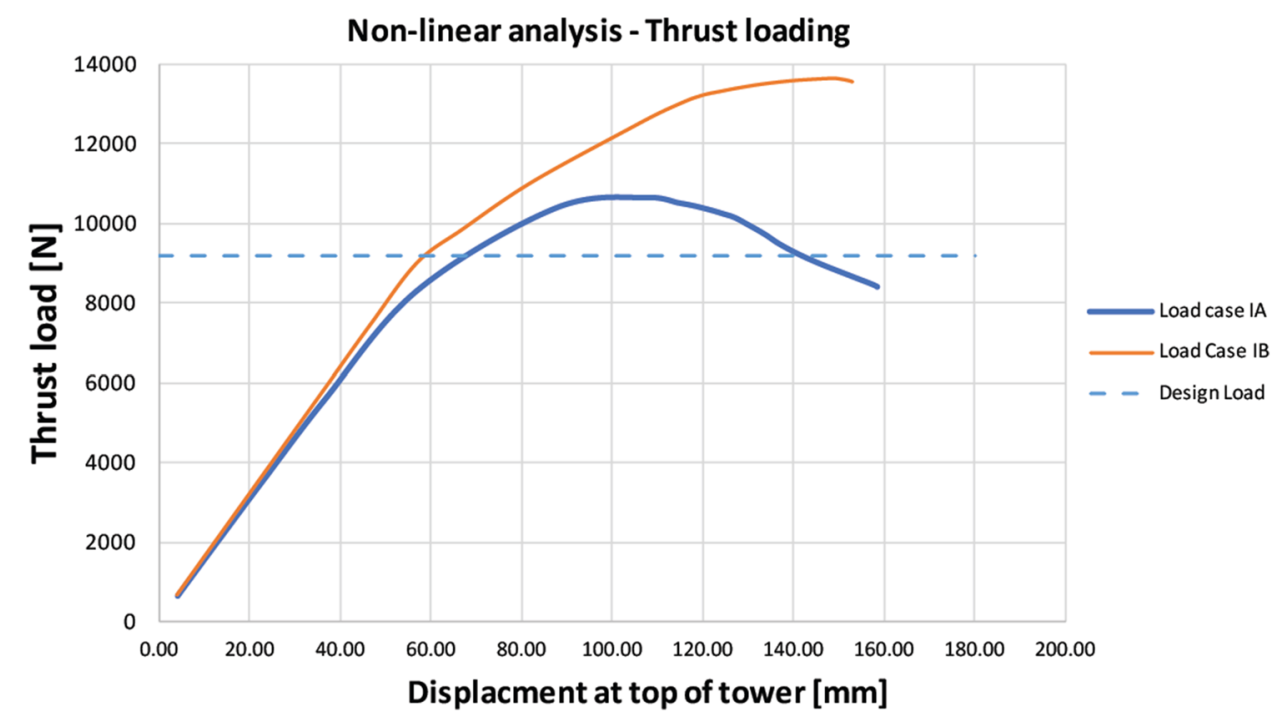

resisted for perpendicular loading (Load Case IA) was $10,628 \mathrm{~N}$ at a maximum deflection of $107 \mathrm{~mm}$, and for diagonal loading (Load Case IB) it was $13,648 \mathrm{~N}$ with a maximum deflection of $149.2 \mathrm{~mm}$. The result indicates that the tower should not fail by buckling during operation. The design load should preferably be located in the linear portion of the graph (Fig. 12). For Load Case IB, the design load is well within the linear part of the graph; however, for Load Case IA it is located in a region where the stiffness begins to decrease slightly. An observation that can be made is that for the perpendicular load case, the graph exhibits softening post-buckling behaviour after exceeding the peak load. This does not happen for the diagonal load case. Another difference between the two load cases is that upon reaching approximately half the design load, the diagonal model starts exhibiting a stiffer response than the perpendicular load case. The non-linear buckled shape for both load cases is shown in Fig. 13 for Load Case IA and Fig. 14 for Load Case IB.

In both cases, the main members were the members most susceptible to local buckling, together with slight buckling of the cross and horizontal members. In the perpendicular Load Case IA, both main legs, which are in compression, failed simultaneously. The main members generally failed at the unsupported span between the horizontal members. In both load cases, main member failure happened between the second and third, or between the third and fourth horizontal members (the first horizontal member is closest to the ground).

Figures 15 and 16 show the rotation plots of the model nodes for the non-linear solutions in cases of gyroscopic moment loading. Load Case IIA is for perpendicular loading, while Load Case IIB is for diagonal loading. The moment load versus rotation curves are illustrated in Fig. 17.

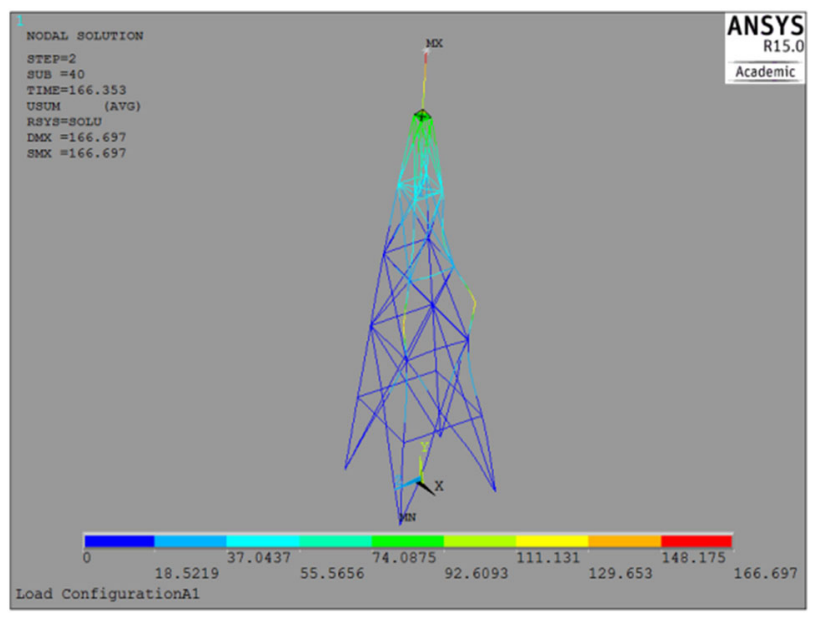

Fig. 13 Displacement contour plot for Load Case IA-perpendicular thrust load

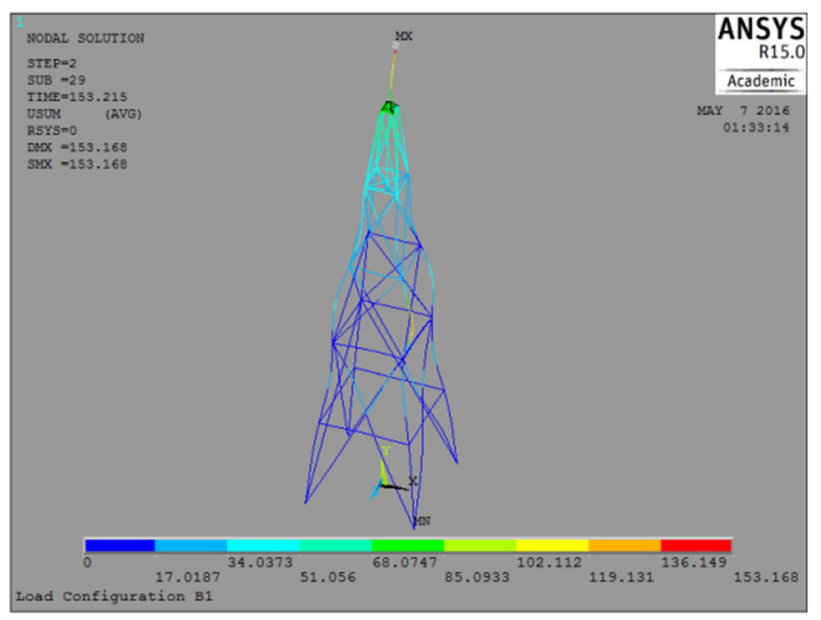

Fig. 14 Displacement contour plot for Load Case IB-diagonal thrust load 


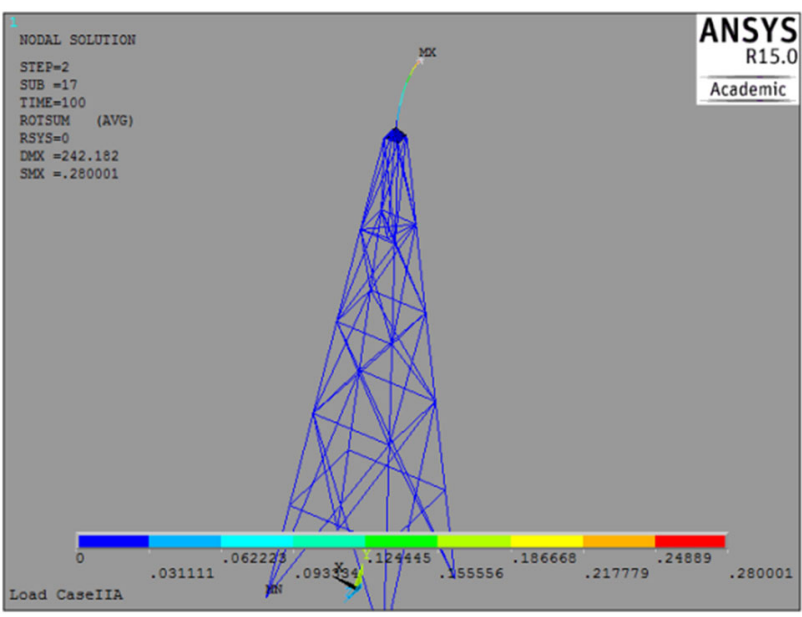

Fig. 15 Rotational displacement contour plot for Load Case IIAperpendicular moment load

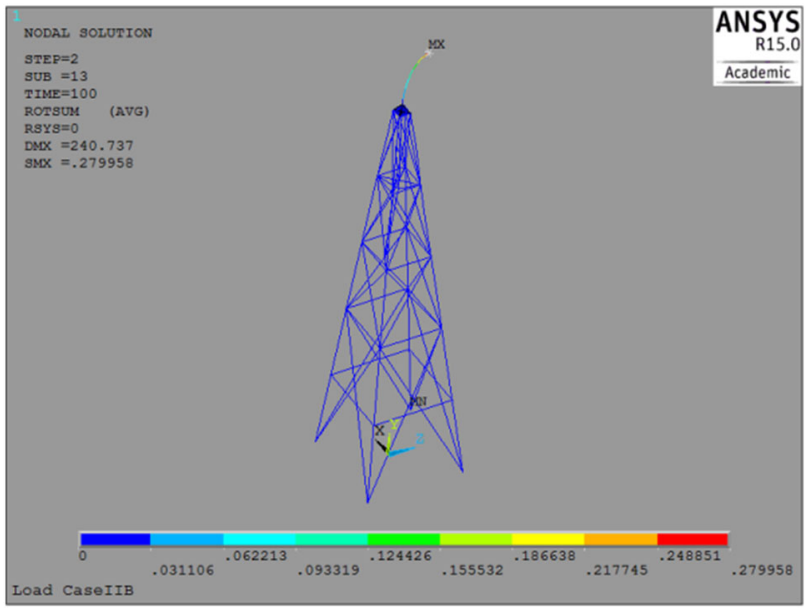

Fig. 16 Rotational displacement contour plot for Load Case IIBdiagonal moment load
A moment of about $39 \mathrm{kN}$ m was reached in the last converged solution and linear behaviour resulted until a load of $35 \mathrm{kN} \mathrm{m}$ was attained. The structure is therefore capable of resisting the $6.7 \mathrm{kN} \mathrm{m}$ yawing load, including the factor of safety. For both the diagonal and the perpendicular application of the moment load, the curves obtained were identical.

For all four load cases considered in the non-linear analysis, there were parts of the structure that went into the plastic state when near the collapse load. Figure 18 shows the contour plot for the von Mises stress for Load Case IA and a zoomed part of the angle member. The figure shows that the extreme ends of the section are in the material plastic region.

The non-linear analysis could be further used to study pseudo tower models that may have suffered damage while on site after a number of years in service. Therefore, a similar check as explained above could be made to determine whether existing towers are capable of withstanding the loads attributed to the new electricity generating SWT. Additional models can be created to simulate different kinds of initial deformations having different magnitudes and positions. All damage and out-of-plane misalignment must be within the limits as dictated by EN1993-1-1 [26], otherwise the structure would require repair.

\section{Lattice tower full-scale testing}

MSA EN 61400-2:2006 [32] requires a full-scale test to validate the numerical models of the turbine tower and to confirm that the supporting structure can carry the design load. The full-scale load test would also check for any manufacturing or materials defects which were not
Fig. 17 Gyroscopic moment load vs. rotation for non-linear models

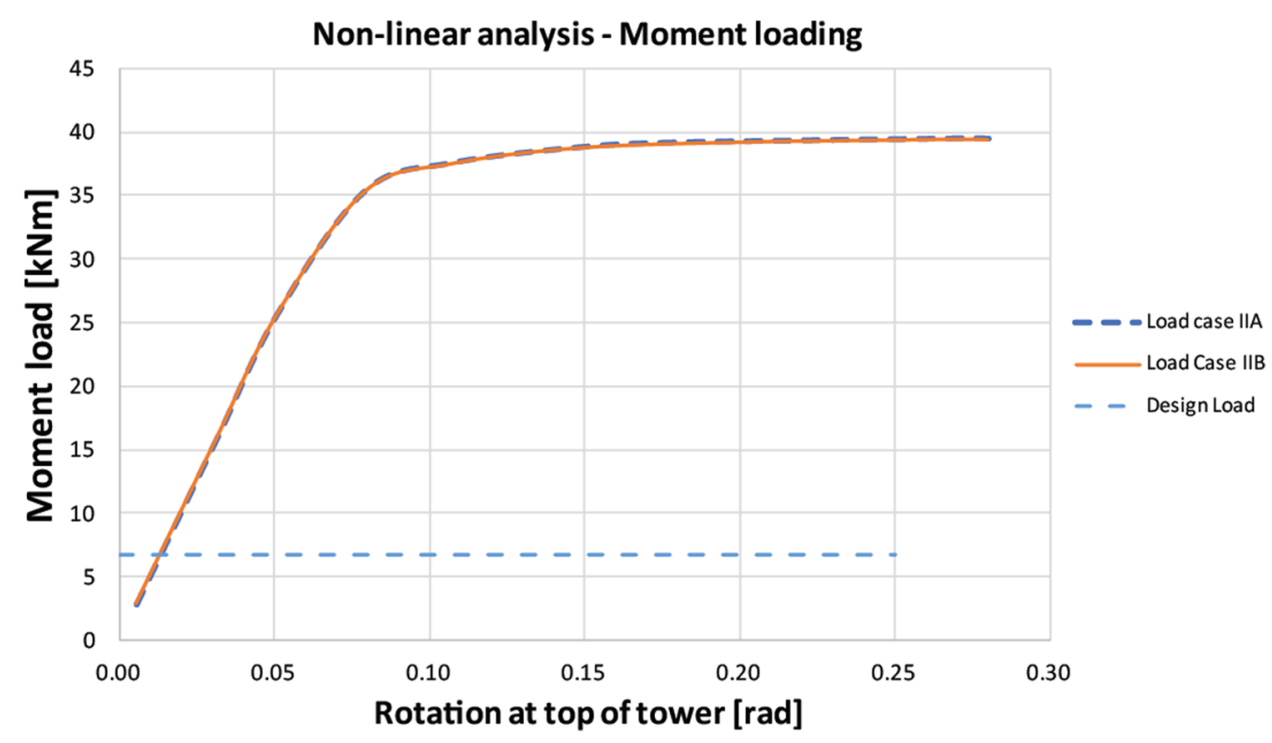




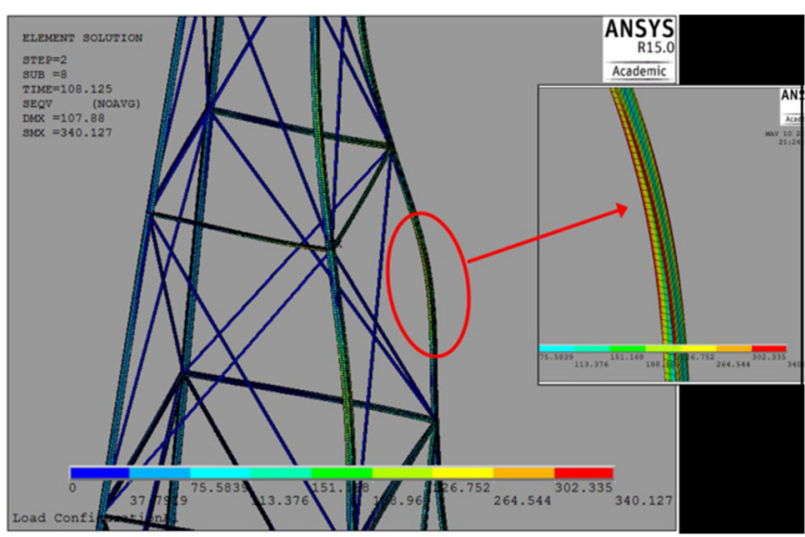

Fig. 18 Contour plot for the von mises stress for Load Case IA

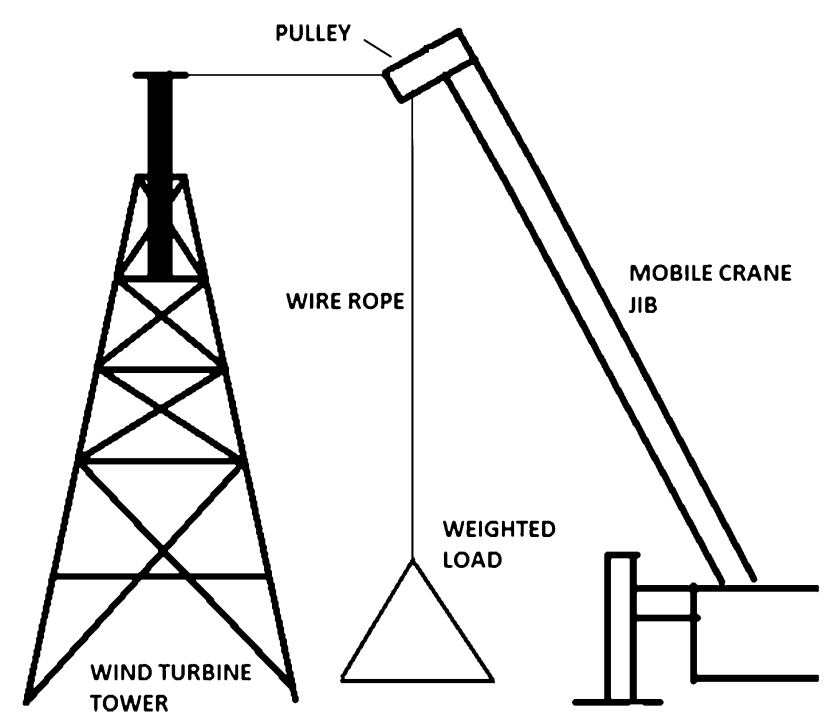

Fig. 19 Schematic diagram of the static tower test [2]

accounted for in the numerical models and theoretical analysis. Figure 19 shows the schematic diagram of the test setup.

The wind generated thrust was simulated by a cable going over the sheaves of a mobile crane and loaded at ground level. For this test configuration, the crane boom load had both horizontal and vertical components, and therefore the capacity of the crane was calculated, keeping in mind the loading configuration that was different from the usual crane operation in the vertical direction. The test load was applied both in the perpendicular and diagonal directions relative to the tower, analogous to Load Cases IA and IB. The gyroscopic moment load cases were not applied during the full-scale test mainly because in terms of structural integrity, these were the least detrimental to the tower structure as compared to the thrust load cases. A load cell was used to measure the load being applied and the structural response of the whole tower was visually checked continuously. Tower members in compression were checked for any signs of buckling. Strain gauges were fixed at certain points on the structure and the resulting strains compared to those calculated using the FE models. Figure 20 shows the location of the strain gauges. The same strain gauges used for the tower test would also be used for wind load monitoring after the wind turbine was installed. For this reason, a number of gauges were installed around the top mast in pairs to be used for wind thrust measurement during wind turbine testing. The position of these gauges was chosen to be about $200 \mathrm{~mm}$ above the reinforcing web plates so as not to capture any stress concentration effects due to the transition. For all members, axial strain was measured and a quarter-bridge configuration was used in the strain gauge circuits [34]. In this configuration, a single active strain gauge element was mounted in the direction of axial, or bending strain of the member.

Long lead wires had to be used from the location of the strain gauge to the data acquisition system. For example for the top mast gauges, the lead wires were about $14 \mathrm{~m}$ long. For this reason, a three-wire circuit as opposed to using two wires was adopted. The benefits of the three-wire circuit include intrinsic bridge balance, automatic compensation for the effects of lead wire temperature changes on the bridge balance and increased measurement sensitivity compared to the two-wire configuration. The three-wire configuration is the recommended configuration for quarter-bridge strain gauge circuits for static strain measurement [34-36]. Foil-shielded cable was used to protect the integrity of the gauges' signal from electrostatic discharge and radio frequency noise. This was highly important since the tower acts as a large antenna which can pick up unwanted noise. The earth wire of each cable was connected to an earth terminal. For the upper gauges, 12-core multi-stranded wire was used and 8-core data cable was used for the gauges at ground level. In both cases, the wires' outer PVC sheath was specified to be UV protected.

The data acquisition system was located in a small room under the tower structure. For the top mast, at every location two gauges were installed near each other in the same vertical axis (Fig. 21). After soldering the lead wires, all wiring was tested for any defects using an Ohm metre and portable strain gauge indicators. The strain reading error was calculated to be approximately $\pm 25 \mu \varepsilon$ [35].

A protective coating was applied to the strain gauges to protect against water ingress and UV radiation. This consisted of paintbrush applied nitrile rubber on the soldered connections, a pliable butyl rubber to prevent moisture ingress and neoprene rubber coatings for mechanical protection covered with aluminium tape to protect against the sun's UV rays. 
Fig. 20 Strain gauges location on the tower

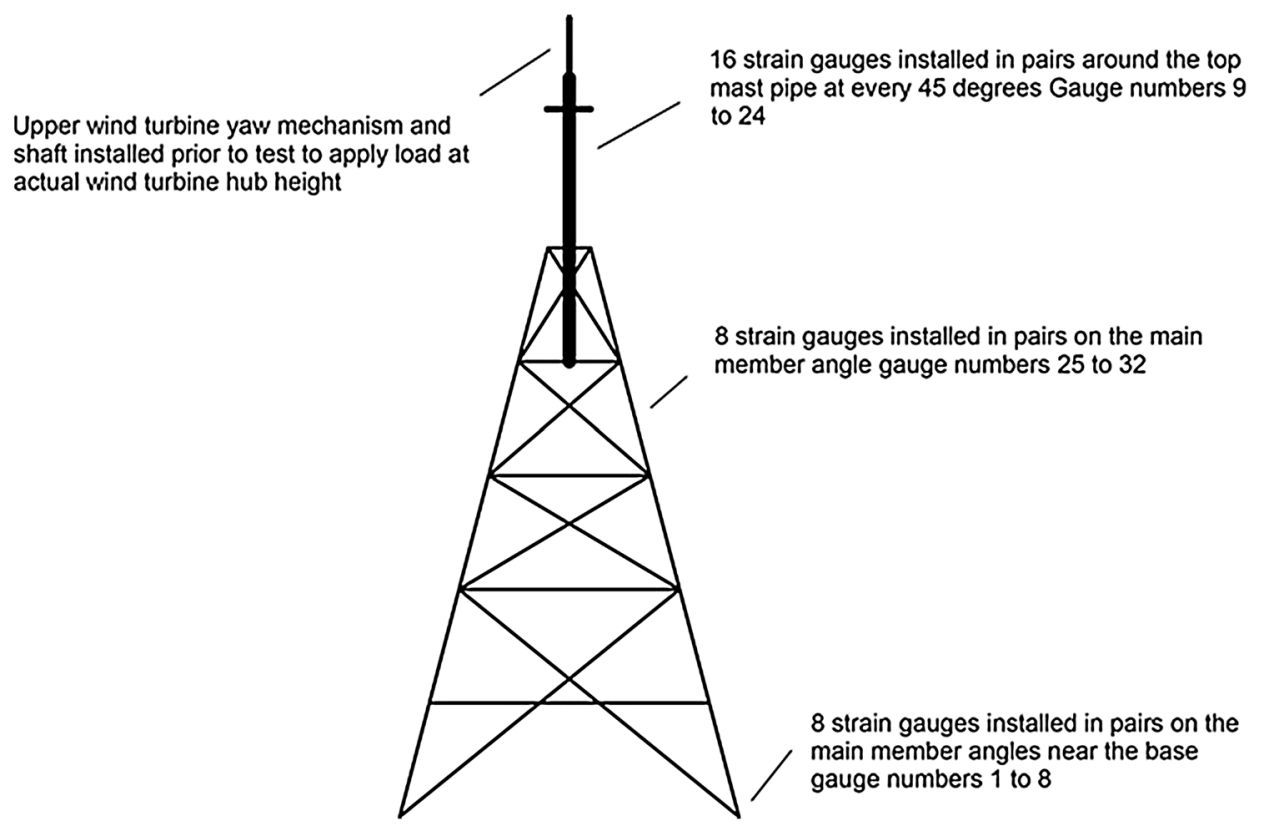

that for the top mast and tower members, the 1st principal stress direction was along their axial direction, with the other two principal directions giving a negligible strain value. Therefore, strain gauge readings were converted to stress values using only the material's Young's modulus values. Tables 1 and 2 show the stress and strain results at the maximum loads for the two different directions of thrust loading.

The maximum stress values are well below the actual material yield limit of $330 \mathrm{~N} / \mathrm{mm}^{2}$ (326 N/mm $\mathrm{mm}^{2}$ for the top mast) and also well below the allowable limit of $230 \mathrm{~N} /$ $\mathrm{mm}^{2}$ (227 N/mm $\mathrm{m}^{2}$ for the top mast). On full unloading, the maximum permanent strain was located in the main members at the second panel (between the third and fourth horizontal members), where slight buckling deformation was observed. The permanent strain value was of $17 \mu \varepsilon$ which, with the value $E$ of $208 \mathrm{GPa}$, results in a stress of 3.54 MPa. This value is quite small (smaller than the expected error) and similar to the FE results, thus indicating that the structure did not suffer permanent plastic deformation. This small offset value could have also occurred due to drift in the strain reading during the test. The test therefore confirmed that the support structure can resist the loading as per MSA EN61400-2:2006 [32].

For the experiment, the strain gauge readings were zeroed just before loading with the transverse thrust. Thus, the strain due to the weight effect of the members was not recorded by the strain gauge indicator. In order to compare the experimental strain results with the numerical models, some slight modifications were therefore implemented in the non-linear FE models. For the FE model, the mass element on top of the mast representative of the wind 
Table 1 Thrust load in perpendicular direction (9476 N) (Load Case IA)

Table 2 Thrust load in diagonal direction $(9084 \mathrm{~N})$ (Load Case IIB)

\begin{tabular}{llc}
\hline & Maximum strain, $\mu \varepsilon$ & Maximum stress, N/mm ${ }^{2}$ \\
\hline Top mast & 673.5 & 154.50 \\
Base of main members & 207.0 & 43.16 \\
Main members at the 2nd panel & 247.5 & 51.48 \\
\hline
\end{tabular}

\begin{tabular}{llc}
\hline & Maximum strain, $\mu \varepsilon$ & Maximum stress, N/mm ${ }^{2}$ \\
\hline Top mast & 649.5 & 148.10 \\
Base of main members & 258.5 & 53.77 \\
Main members at the 2nd panel & 303.5 & 63.13 \\
\hline
\end{tabular}

turbine weight was ignored, and gravity loading was removed after obtaining the new, non-linear solution. This was done as a third load step in which gravity was removed. Thus, any effects in the non-linear solution due to the tower members' weight were included, but then the third load step removed its effect on the resulting strains. For the perpendicular load case, the comparison of results between strains obtained experimentally and using FEA is shown in Figs. 22, 23, 24 and 25. In these plots, the error bars for strain, deflection and load are included. The error bars for the load are not visible since the error was very small compared to the range being plotted on the graphs. Figure 22 shows the strain results for the top mast in the case of perpendicular loading in which only the maximum and minimum strain values are shown for clarity. The experimentally measured strains remain linear in relation to the load, behaviour similar to that obtained in the FE results. Other observations are that the experimental and FEA load-strain lines have almost the same slope and that the FEA strain is within $\pm 35 \mu \varepsilon$ of the measured experimental strain.
Figure 23 shows the comparison for four gauges in the case of perpendicular loading (Load Case IA): two located in a compression-loaded main member, and two in a tensile-loaded main member. The FEA results for these locations lie within the error range of the experimental strain values obtained.

Figure 24 shows the comparison for the strain gauges located on the main members at ground level. Only two main members are shown for clarity, as the load in the other two main members is symmetric. At this location, the experimental strains are more dispersed from each other, which may imply that the main member has a bending moment acting and creating different strain levels on the sides of the angle member. This can occur due to some slight side sway caused by the fact that the angle sections are open sections, as opposed to closed sections. It is to be noted that this dispersion does not manifest itself in the FE results mainly because of the one-sided direction of predeformation imposed on the unloaded model.

Figure 25 shows the plots of the strain gauges that recorded the maximum strain at the instrumented locations.

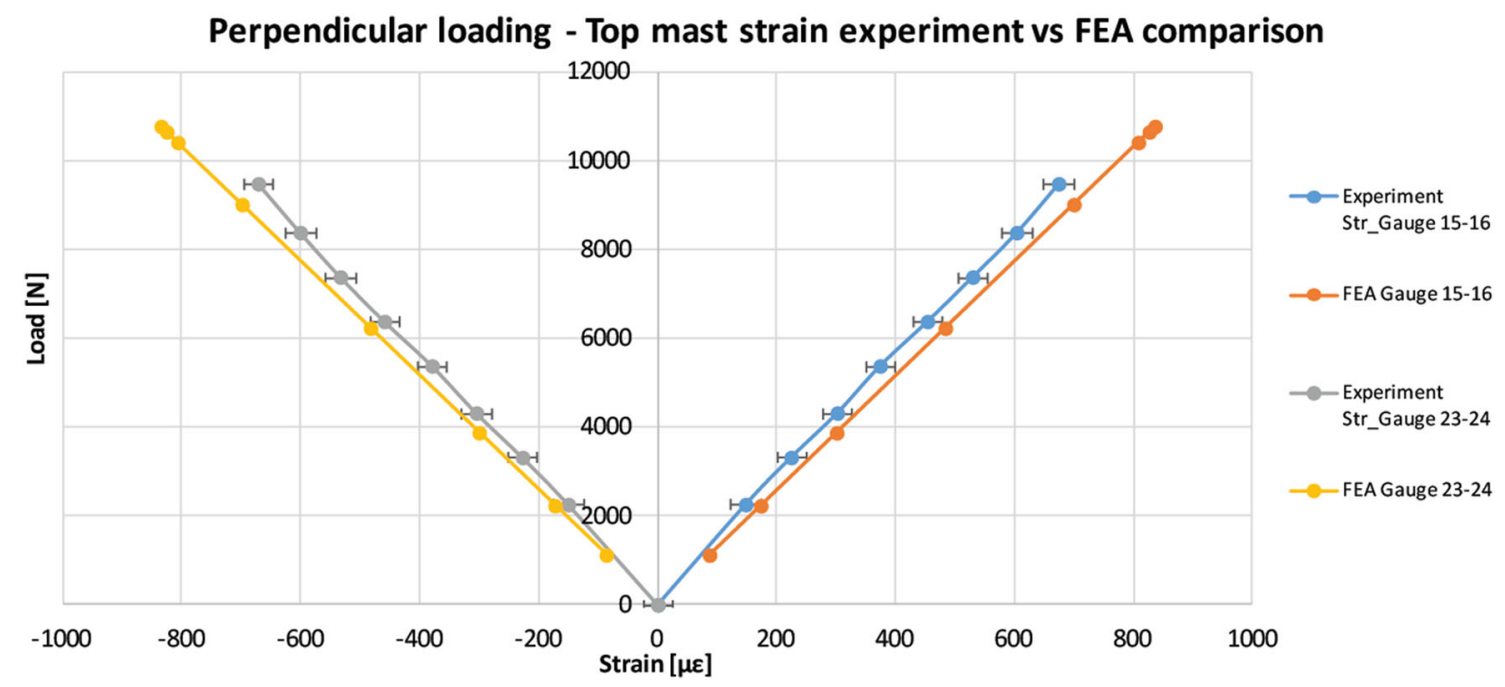

Fig. 22 Load Case IA (perpendicular loading) Top mast maximum and minimum strain comparison 


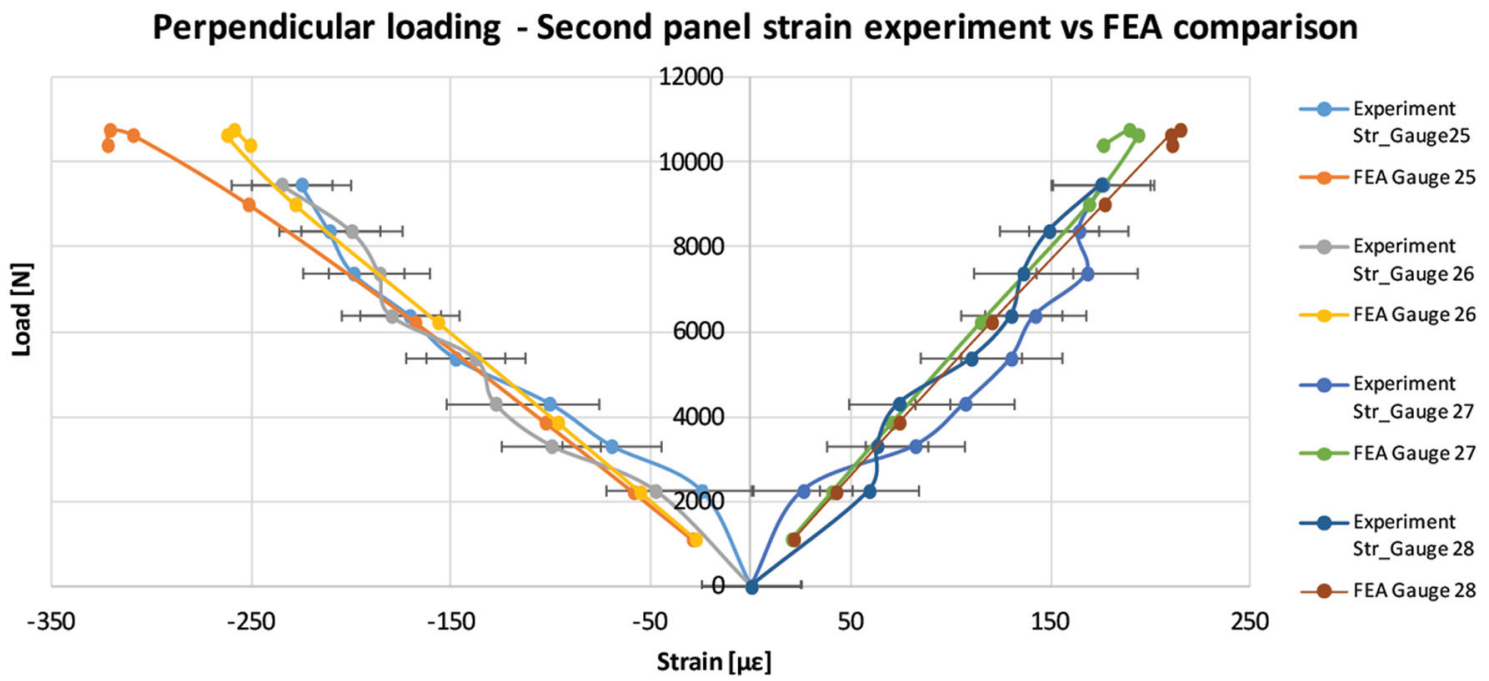

Fig. 23 Load Case IA (perpendicular loading) second panel strain readings for compressive gauges 25 \& 26 and tensile gauges 27 \& 28 loaded main members

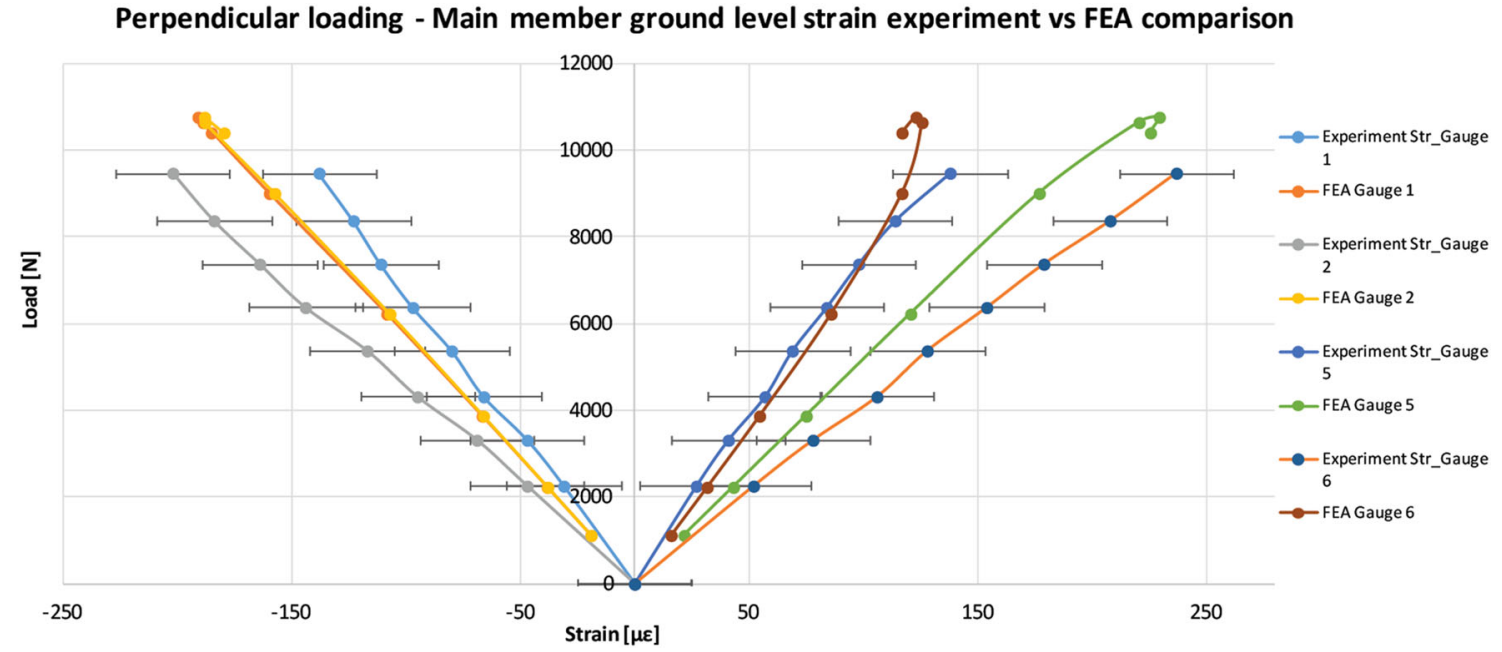

Fig. 24 Load Case 1A (perpendicular loading) ground level strain readings for compressive gauges 1 \& 2 and tensile gauges 5 \& 6 loaded main members

Graphs for both loading and unloading are shown and in general both follow the same path. As expected, the maximum strain for the top mast occurred on the farthest side, in line with the load direction. For the main members, the load was distributed symmetrically in compression and tension with minor differences in strain. In the unloading strain, a slight deviation was recorded, but then this followed the same path as for the loading case. The maximum offset between loading and unloading can be observed on the second panel, where buckling deflection was observed during the experiment.

For the case of diagonal loading, plots similar to the one above were obtained. These are not shown here for brevity. Most graphs similar to the ones shown in Figs. 22, 23, 24 and 25 confirmed that the numerical model was in good agreement with the experimental measured strain.

\section{Conclusions}

Linear elastic and full non-linear buckling analyses were performed on the existing SWT lattice tower. Four load cases were applied in accordance with MSA EN614002:2006 [32].

The overall performance of the installed tower was found to be capable of resisting all the applied loads in conformity with this standard. The failure criterion used in the linear elastic model was the maximum member 


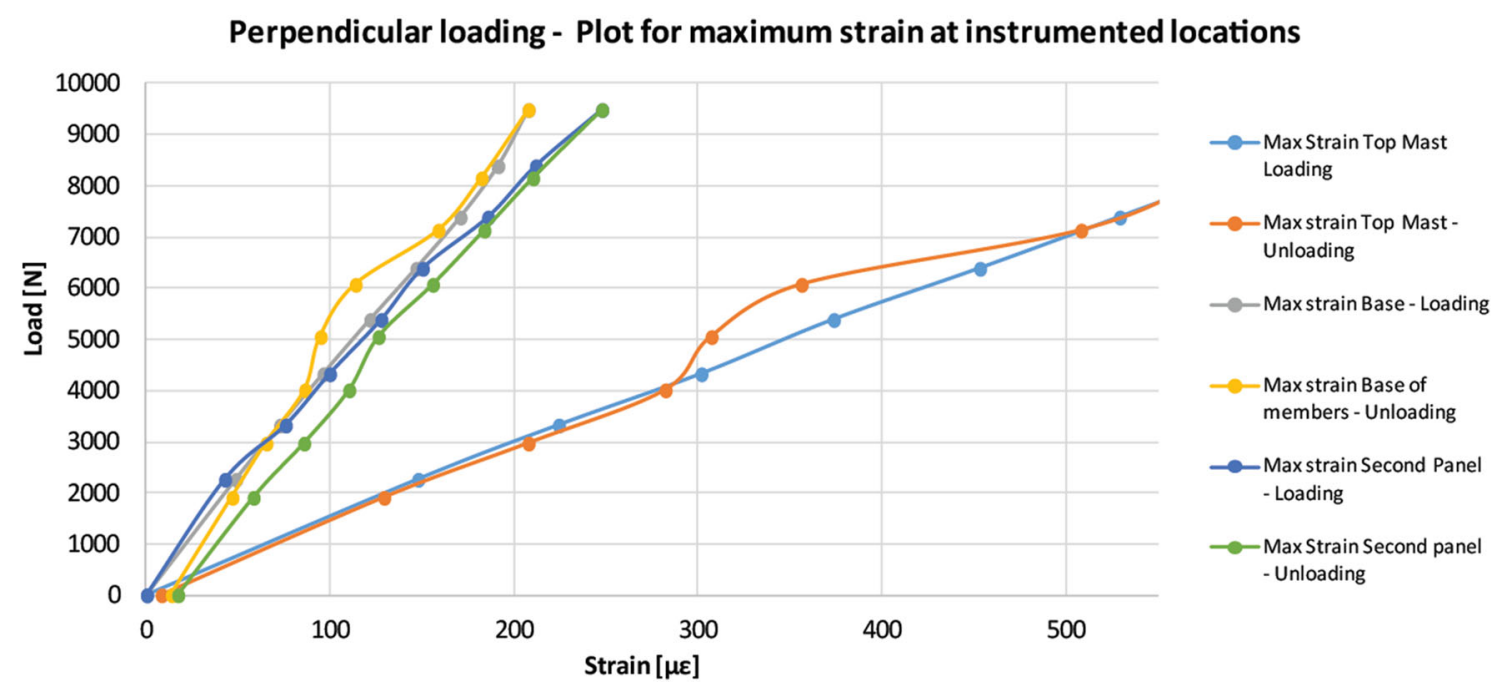

Fig. 25 Load and unload strain values at selected strain gauges

stresses. These were compared to the allowable stress imposed by MSA EN61400-2:2006 [32]. At the design load, no part of the tower exceeded the allowable limit, except for small stress concentration regions in the lattice tower mast transition piece. These stresses do not contribute to overall structural or localised buckling and can later on be used for a fatigue assessment. Apart from these regions, the maximum stresses occurred mainly in the top mast component.

Linear elastic analysis is much simpler than non-linear analysis but does not take into account various factors including material plasticity and pre-deformations in the geometry of the members. These factors can lead to buckling instability which cannot be modelled in an elastic analysis. In this paper, non-linear analysis was used to calculate the buckling load of the structure for the various load cases. The results showed that at the design loads, the tower has additional reserve capacity against buckling failure. It was found that the buckling load is very sensitive to both the value and the mode of pre-deformation applied to the model. Various models were used to find the worst initial deformation that causes the tower not to conform to the relevant EN standards [26, 32].

Furthermore, the non-linear method presented can be used to assess existing lattice towers having various degrees of damage, corrosion and pre-deformations. These can then be repaired as necessary in order to mount the newly developed SWT. Although secondary braces are usually subjected to very small axial loads, the results showed that their existence greatly enhances the buckling capacity of the structure by reducing the effective length of the main members. During the non-linear analysis, the minimum eigenvalue buckling load does not necessarily mean that it will result in the lowest buckling capacity so that a number of different eigenvalue modes need to be considered.

The non-linear analysis showed that the buckling capacity of the tower is highly dependent on the main members. Therefore, the tower buckling capacity can be improved either by increasing the density of intermediate members to reduce the unsupported span or by increasing the section size of the main member.

The non-linear FE models approached the real-world behaviour of the tower in many aspects. The method of failure by buckling determined from these models was confirmed during the experiment. The tower was not tested to the point of failure since it had to be utilised for the installation of the SWT. However, testing continued until the structure was on the onset of elastic buckling at the design load. The location most likely to sustain buckling failure was also in good agreement with what was predicted by the non-linear FEA. At the strain gauge locations, the stresses did not exceed the allowable limit at the design load. Once again, this is in agreement with what was predicted by the non-linear models.

Strain comparison between the non-linear numerical models and the experiment agreed fairly well in tensileloaded areas, whereas a more divergent relationship was seen for members under compression. Overall, considering the uncertainties involved, the strain measurements for all locations were well within the range predicted by FEA.

Acknowledgements The authors wish to acknowledge the use of the ANSYS Mechanical software academic research license, the financial grant provided by the former Maltese Ministry for Resources and Rural Affairs (MRRA, 2007) and the Government Experimental Farm at Ghammieri, Marsa, Malta. 
Open Access This article is distributed under the terms of the Creative Commons Attribution 4.0 International License (http://crea tivecommons.org/licenses/by/4.0/), which permits unrestricted use, distribution, and reproduction in any medium, provided you give appropriate credit to the original author(s) and the source, provide a link to the Creative Commons license, and indicate if changes were made.

\section{References}

1. ANSYS Mechanical Academic Research, Canonsburg, USA, Release 15

2. Muscat M., Sant T., Farrugia R.N., Caruana C., Axisa R.: Design and construction of a small multi-bladed wind turbine for the suburban and rural environment, Europe and the Mediterranean, towards a sustainable built environment-SBE16, Malta (2016)

3. Martin, L., Purkiss, J.: Structural design of steelwork to EN1993 and EN1994, 3rd edn. Butterworth Heinmann, London (2008)

4. Coates, R., Coutie, M., Kong, F.: Structural analysis. Chapman \& Hall, London (1988)

5. Fang, S.J., Roy, S. and Kramer, J.: Transmission structures, In: Chapter 15-handbook of structural engineering, CRC Press, New York (1999)

6. Lee, P.S., McClure, G.: Elastoplastic large deformation analysis of a lattice steel tower structure and comparison with full-scale tests. J. Constr. Steel Res. 63, 709-717 (2007)

7. Zhangqi, W., Zeming, S., Wenqiang, J.: Theoretical and experimental research on joint slippage effects of lattice angle steel tower. Appl. Mech. Mater. 477-478, 660-665 (2014)

8. Zhuge, Y., Mills, J.E., Ma, X.: Modelling of steel lattice tower angle legs reinforced for increased load capacity. Eng. Struct. 43, 160-168 (2012)

9. Junior, P.A.A.M, et al.: Design of lattice wind turbine towers with structural optimization. Int. J. Eng. Res. Appl. ISSN: 224-9622, 4(8), (Version 5), August 2014, pp 38-51

10. Adhikari, R.C., Wood, D.H., Sudak, L.: Design procedure for tubular lattice towers for small wind turbines. Wind Eng. 38(4), 359-376 (2014)

11. del Coz Diaz, J.J., et al.: A study of the collapse of a WWII communications antenna using numerical simulations based on design of experiments by FEM. Eng. Struct. 32, 1792-1800 (2010)

12. Jiang, W.Q., et al.: Accurate modelling of joint effects in lattice transmission towers. Eng. Struct. 33, 1817-1827 (2011)

13. Rao, N.P., Knight, G.S., Mohan, S., Lakshmanan, N.: Studies on failure of transmission line towers in testing. Eng. Struct. 35, 55-70 (2012)

14. Stamatopoulos, G.N.: Assessment of strength and measures to upgrade a telecommunication steel tower. Int. J. Steel Struct. doi:10.1007/s13296-013-2011-8

15. Lu, C., Ma, X., Mills, J.E.: Modeling of retrofitted steel transmission towers. J. Constr. Steel Res. 112, 138-154 (2015)

16. Szafran, J.: An experimental investigation into failure mechanism of a full-scale $40 \mathrm{~m}$ high steel telecommunication tower. Eng. Fail. Anal. 54, 131-145 (2015)
17. Szafran, J., Rykaluk, K.: A full scale experiment of a lattice telecommunication tower under breaking load. J. Constr. Steel Res. 120, 160-175 (2016)

18. Baran, E., Akis, T., Sen, G., Draisawi, A.: Experimental and numerical analysis of a bolted connection in steel transmission towers. J. Constr. Steel Res. 121, 253-260 (2016)

19. Asgarian, B., Eslamlou, S.D., Zaghi, A.E., Mehr, M.: Progressive collapse analysis of power transmission towers. J. Constr. Steel Res. 123, 31-40 (2016)

20. Kroeker, D.: Structural analysis of transmission towers with connection slip modelling. University of Manitoba Winnipeg, Manitoba (2001)

21. da Silva, J.G.S., Vellasco, P.D.S., de Andrade, S.A., de Oliveira, M.I.R.: Structural assessment of current steel design models for transmission and telecommunication towers. J. Constr. Steel Res. 61, 1108-1134 (2005)

22. Taillon, J.Y., Legeron, F., Prud'homme, S.: Variation of damping and stiffness of lattice towers with load level. J. Constr. Steel Res. 71, 111-118 (2012)

23. Nezamolmolki, D., Shooshtari, A.: Investigation of nonlinear dynamic behaviour of lattice structure wind turbines. Renew. Energy 97, 33-46 (2016)

24. Solari, G., Calotescu, I.: Along wind load effects on free-standing lattice towers. J. Wind Eng. Ind. Aerodyn. 155, 182-196 (2016)

25. Brockenbrough, R.L., Merritt, F.S.: Structural steel designer's handbook, 3rd edn, pp. 13.35-13.49. McGraw-Hill, New York (1999)

26. EN1993-1-1, Eurocode 3: Design of steel structures-Part 1-1: general structural rules and rules for buildings, Standards and Metrology Institute, Malta Competition and Consumer Affairs Authority (MCCAA), Blata 1-Bajda, Malta (2005)

27. Leea, P.S., McClureb, G.: Elastoplastic large deformation analysis of a lattice steel tower structure and comparison with fullscale tests. J. Constr. Steel Res. 63(5), 709-717 (2007)

28. Albermani, F. and Kitipornchai, S.: Numerical simulation of structural behaviour of transmission towers, Journal of ThinWalled Structures, 41 (2003)

29. Rao, N., Kalyanaraman, V.: Non-linear behaviour of lattice panel of angle towers. J. Constr. Steel Res. 57, 1337-1357 (2001)

30. Albermani, F., Kitipornchai, S., Chan, R.: Failure analysis of transmission towers. Eng. Fail. Anal. 16, 1922-1928 (2009)

31. Rao, N.P., Knight, G.S., Lakshmanan, N., Iyer, N.R.: Investigation of transmission line tower failures. Eng. Fail. Anal. 17, 1127-1141 (2010)

32. IEC61400-2, Wind turbines-part 2: design requirements for small wind turbines: Standards and Metrology Institute, Malta Competition and Consumer Affairs Authority (MCCAA), Blata 1-Bajda, Malta (2006)

33. Stoman, S.: Stability criteria for X-bracing systems. J. Eng. Mech. ASCE 114(8), 1426-1434 (1988)

34. Micro-Measurements, Tech Tip TT-612-the three-wire quarterbridge circuit, Vishay precision group, 951 Wendell Blvd., Wendell, NC 27591, USA

35. O. E. Inc., Practical strain gauge measurements. www.Omega. com (1999)

36. Vaughan, J.: Application of B \& K equipment to strain measurements, Bruel and Kjaer (1975) 